\title{
EDUCAÇÃO INCLUSIVA, LEGISLAÇÃO E IMPLEMENTAÇÃO
}

\author{
INCLUSIVE EDUCATION, LEGISLATION AND IMPLEMENTATION
}

EDUCAIÓN INCLUSIVA, LEGISLACIÓN E IMPLEMENTACIÓN

\author{
ARRUDA, Gabriela Alves de \\ DIKSON, Dennys²
}

\begin{abstract}
RESUMO
Esse artigo apresenta uma discussão inicial de acompanhamento e evolução da legislação sobre educação inclusiva no Brasil, especificamente a Declaração de Salamanca, o Decreto n 7.611/2011, a Resolução CNE/CEB n 4/2009 e a Lei n 13.146/2015. O ordenamento jurídico que baseia a educação especial e inclusiva é amplo e tem conquistado avanços. É um assunto complexo e tem apontado que, mesmo a passos lentos, as políticas públicas vêm visivelmente avançando. A partir da análise discursivoqualitativa e da efetividade desse arcabouço normativo, apresentamos questões referentes a princípios e concepções, metas traçadas e a lenta - mas visível - implementação de políticas de inclusão no sistema educacional brasileiro. Foi possível, então, evidenciar que ainda são necessárias diversas ações que possibilitem a uma real execução e institucionalização das leis que possam influenciar a prática cotidiana nas escolas, através de condições adequadas para o acesso dos alunos com necessidades educacionais especiais, algum tipo de deficiência ou altas habilidades/superdotação.
\end{abstract}

Palavras-chave: Legislação. Educação Inclusiva. Implementação.

\section{ABSTRACT}

This article presents an initial discussion of monitoring and development of legislation on inclusive education in Brazil, specifically the Declaration of Salamanca, Decree No. 7,611 / 2011, the CNE / CEB Resolution No. 4/2009 and Law No. 13,146 / 2015. The legal system that is based on the special and inclusive education is broad and has won advances. It is a complex matter and has pointed out that, even at a slow pace, public policies have visibly advancing. From the discursive and qualitative analysis of the effectiveness of this legal framework, we present issues relating to principles and concepts, set targets and slow - but visible implementation of inclusion policies in the Brazilian educational system. It was possible, then, to show that they are still required several actions that enable a real implementation and institutionalization of laws that can influence daily practice in schools through appropriate conditions for access of students with special educational needs, a disability or high abilities / giftedness.

Keywords: Legislation. Inclusive education. Implementation.

\section{RESUMEN}

En este trabajo se presenta una discusión inicial de la vigilancia y el desarrollo de la legislación sobre educación inclusiva en Brasil, específicamente la Declaración de Salamanca, el Decreto N7.611 / 2011, la CNE / CEB Resolución N` 4/2009 y la Ley $\mathrm{N} \bullet 13.146$ / 2015. El sistema legal que se basa en la educación especial e inclusiva es amplia y ha ganado avances. Es un asunto complejo y ha señalado que, aunque a un ritmo lento, las políticas públicas han avanzando visiblemente. A partir del análisis discursivo y cualitativa de la efectividad de este marco legal, se presentan cuestiones relativas a los principios y conceptos fijar objetivos y lentos - pero visible - la aplicación de las políticas de inclusión en el sistema educativo brasileño. Era posible, entonces, para demostrar que aún se requieren varias acciones que permitan una implementación real y la institucionalización de las leyes que pueden influir en la práctica diaria en las escuelas a través de condiciones adecuadas para el acceso de los estudiantes con necesidades educativas especiales, una discapacidad o alta habilidades / superdotación.

Palabras clave: Legislación. La educación inclusiva. Implementación.

\footnotetext{
1 Faculdade de Integração do Sertão- FIS - Serra Talhada - Pernambuco - Brasil.

2 Universidade Federal Rural de Pernambuco - UFRPE - Recife - Pernambuco - Brasil.
} 


\section{INTRODUÇÃO}

Este artigo pretende contribuir para as discussões a respeito do processo de inclusão de alunos com deficiência na rede regular de ensino, a partir de um estudo acerca da efetividade do arcabouço jurídico (a Declaração de Salamanca, o Decreto No 7.611/2011, a Resolução CNE/CEB nº 4/2009 e a Lei $n^{\circ}$ 13.146/2015) que lastreia a implementação do acesso à educação e à inclusão escolar destes alunos.

A Declaração de Salamanca e Linha de Ação sobre Necessidades Educativas Especiais UNESCO, 1994 (BRASIL, 2016), é o documento destaque que melhor expressa a perspectiva da educação inclusiva. Eventos internacionais impulsionadores de seus pressupostos foram a Conferência Mundial de Educação para Todos, realizada em Jomtien (Tailândia) em 1990, e o Fórum Mundial de Educação, ocorrido no ano 2000 em Dakar (Senegal). Ambos defenderam princípios pautados na dignidade e nos direitos humanos. No Brasil, como em outras partes do mundo, os desafios para a conquista da educação inclusiva são constantes e significativos. Algumas bases legais que sustentam o processo desempenham um papel essencial para sua efetivação, as quais ensejaram a realização deste trabalho, com o objetivo destacar algumas análises para verificar se há efetividade na aplicação dessas leis, ou seja, se as políticas de educação inclusiva e os ditames do acesso à educação às pessoas com deficiência, estão sendo realmente implementadas.

Iniciaremos com uma breve menção à evolução histórica da educação especial até 1990 , quando ocorreu o primeiro evento internacional que formalizou a "Educação para Todos" como plataforma básica para os sistemas educacionais da comunidade mundial: a Conferência Mundial sobre Educação para Todos. Em seguida, os aspectos relevantes ao tema deste artigo, propostos na Declaração de Salamanca (1994), sobre a educação especial, serão apresentados e discutidos. Num terceiro momento, discutiremos as principais legislações brasileiras acerca da educação inclusiva, avaliando seus processos de efetivação. Por fim, nas considerações finais, serão levantados aspectos do contexto brasileiro a serem considerados na adoção e implementação do processo de inclusão.

\section{EDUCAÇÃO ESPECIAL E A PERSPECTIVA DA EDUCAÇÃO INCLUSIVA NO BRASIL: A TRAJETÓRIA DE ALGUMAS LEGISLAÇÕES}

A educação especial, na maioria dos países, tem em um primeiro momento compartilhado de uma mesma situação de segregação e exclusão - os indivíduos são simplesmente ignorados, abandonados e muitas vezes até mesmo assassinados, devido a sua diferença do conceito de normalidade. Durante a Idade Média, a forma de tratamento desses indivíduos se modificava de acordo com as concepções de caridade ou de castigo, esses eram os tipos de tratamento que a sociedade dava a essas pessoas, que acabavam sendo, de uma forma ou de outra, excluídas. 
Durante o surgimento do capitalismo pode-se perceber o interesse da ciência, especificamente da medicina, no que diz respeito à pessoa com deficiência. A partir disso, passa a existir uma certa preocupação com a educação e o processo de socialização desses indivíduos, tidos então como "anormais". Conforme pontua Foucault (2001), os anormais são os que fugiam do padrão de normalidade de comportamento e de estrutura comportamental-social, os que não se enquadravam na normalidade da sociedade. No entanto, esses supostos interesses continuavam com uma ideologia de visão patológica do ser que apresentava deficiência, o que fazia (e ainda faz, em muitos aspectos) a sociedade agir com desprezo com relação a essas pessoas.

Dessa maneira, a história da educação no Brasil, como coloca Ragonesi (1997), tem demonstrado um quadro diferente do que se foi proposto pela primeira constituição Brasileira em 1983, que anunciava a educação primária como obrigatória, gratuita e extensiva a todos os cidadãos. Colocando em foco a educação especial no país, tanto Bueno (1993) quanto Mendes (2001) apresentam como momento da educação especial a criação e implantação do Imperial Instituto dos Meninos Cegos e do Instituto dos Surdosmudos. Porém, influenciados por conflitos políticos, sociais, entre outros, sofreram perdas e se deterioraram. Por mais que aparentassem os institutos europeus, o seu cunho assistencialista não desenvolvia uma educação de fato. Essa política de "favor" limitava o desenvolvimento da educação (BUENO, 1993). Enquanto os institutos brasileiros de educação especial cumpriam sua função de auxílio aos desvalidos, os parisienses, diferentemente, mantinham-se como oficinas de trabalho.

\subsection{Declaração de Salamanca: a gênese de uma Educação Inclusiva}

A partir da Declaração de Salamanca (1994), o Brasil, a exemplo dos demais signatários, começou a implantar políticas de inclusão no ensino regular de alunos com necessidades especiais, por considerarem-nas como a forma mais democrática para a efetiva ampliação de oportunidades para essa população. Essas políticas baseavam-se em um ideal de democracia, cujo principal objetivo era a efetiva ampliação de oportunidades para essa população marginalizada.

Segundo Mendes (2001, p. 28), a ideia da inclusão se fundamenta numa filosofia que reconhece e aceita a diversidade na vida em sociedade. Isto significa garantia de acesso de todos a todas as oportunidades, independentemente das peculiaridades de cada indivíduo no grupo social. Uma escola regular única, capaz de atender todas as crianças é uma determinação da Declaração de Salamanca, voltada para o fim das discriminações e construção de comunidades inclusivas, que se apresentem como um modelo econômico mais acessível, quando destaca que tais escolas provêm uma educação efetiva à maioria das crianças e aprimoram a eficiência e, em última instância, o custo da eficácia de todo o sistema educacional.

Nessa perspectiva, a educação especial envolve um amplo processo de mudanças para a implantação de sistemas educacionais inclusivos, revertendo as propostas convencionais de criar programas especiais para atender, de forma segregada, alunos com necessidades educacionais 
especiais, inserindo os gestores públicos e os profissionais da educação na elaboração de políticas para todos, que contemplem a diversidade humana.

A educação inclusiva é hoje um dos debates mais presentes na educação do país. Nunca antes foi tão discutido o princípio constitucional de igualdade de condições de acesso e permanência na escola, implicando na necessidade de reverter os velhos conceitos de normalidade e padrões de aprendizagem, bem como afirmar novos valores na escola que contemplem a cidadania, o acesso universal e a garantia do direito de todas as crianças, jovens e adultos de participação nos diferentes espaços da estrutura social (DUTRA, 2006, p. 3).

No contexto educacional brasileiro, essa é uma política que gera conflito, provoca reflexão e polêmica acerca das ideias e possíveis caminhos na busca de um novo paradigma educacional que envolve redefinição da organização do sistema e do pensamento pedagógico que fundamentam o processo de ensino e aprendizagem.

O Brasil é pródigo em legislação, o que não é diferente para o tema da Educação Especial. Mas o processo de inclusão não se faz somente com respaldo legislativo. Segundo Bueno (1993), deve-se levar em conta o contexto socioeconômico, planejamento contínuo e avaliação. Ou seja, esta mudança depende da mudança de valores da sociedade como um todo.

O aspecto inovador da Declaração de Salamanca consiste na retomada de discussões sobre as consequências e o encaminhamento de diretrizes básicas para a formulação e reforma de políticas e sistemas educacionais. Mas, antes de tudo, proporcionou uma oportunidade única de colocação da educação especial dentro da estrutura de "educação para todos". Ela promoveu uma plataforma que afirma o princípio e a discussão da prática de garantia de inclusão das crianças com necessidades educacionais especiais nestas iniciativas e a tomada de seus lugares de direito numa sociedade de aprendizagem.

Outrossim, segundo Santos (2000, p. 5):

\begin{abstract}
O conceito de necessidades educacionais especiais passou a incluir, além das crianças portadoras de deficiência, aquelas que estejam experimentando dificuldades temporárias ou permanentes na escola, as que estejam repetindo continuamente o ano escolar, as que sejam forçadas a trabalhar, as que vivem nas ruas ou que moram distantes de qualquer escola, as que vivem em condições de extrema pobreza ou que sejam desnutridas, as que sejam vítimas de guerras e conflitos armados, as que sofrem de abusos contínuos físicos, emocionais e sexuais, ou as que estão fora da escola, por qualquer motivo que seja.
\end{abstract}

Em termos governamentais, isso implicaria na reformulação de políticas educacionais e da implementação de projetos educacionais do sentido excludente ao sentido inclusivo. Uma grande questão que geralmente se coloca sobre este aspecto, em países, regiões ou localidades em que a educação especial já tenha se constituído como um sistema paralelo de ensino, refere-se à onerosidade financeira de tal reformulação. De fato, nenhum começo é fácil. Mas os esforços e investimentos demandados pelo movimento de advocacia de uma educação inclusiva só são onerosos quando vistos numa perspectiva imediatista. 


\section{Decreto No 7.611/2011: a individualização do apoio educacional especializado}

O decreto $n^{\circ} 7.611$, sancionado em 17 de novembro de 2011, dispõe a respeito da educação especial, do atendimento educacional especializado, além de dar outras providências. $O$ presente decreto assegura, em seu artigo $1^{\circ}$, ser dever do Estado oferecer educação às pessoas que necessitem de educação especial, sendo que, para isso, deve garantir um sistema de ensino inclusivo em todos os seus níveis, adotar medidas individualizadas e eficazes de apoio, visando a um ambiente que favoreça o desenvolvimento acadêmico desses alunos, ofertando, ainda, educação especial dentro do ensino regular e apoio técnico e financeiro às instituições privadas especializadas somente em educação especial. É válido retomar aqui que o decreto considera como sendo o público-alvo da educação especial pessoas com deficiência, com transtornos globais do desenvolvimento e, também, com altas habilidades/superdotação.

O documento considera, em seu artigo $2^{\circ}$, que a educação especial deve garantir serviços de apoio especializado que visem a diminuir as barreiras que possam estar impedindo o processo de alfabetização, através de complemento à formação do público-alvo referido anteriormente, com apoio permanente e limitado ao tempo e frequência desse aluno na sala de recursos. Além disso, o atendimento educacional especializado deve integrar o plano pedagógico da escola, abarcar a participação da família, atender às necessidades específicas desses alunos e estar articulado com as demais políticas públicas.

Esse atendimento educacional especializado, conforme o artigo $3^{\circ}$, tem como objetivos tanto garantir acessibilidade à escola e à aprendizagem no ensino regular, como também proporcionar condições de acesso aos serviços de apoio especializados, de acordo com a necessidade de cada um. Tem por finalidade, ainda, garantir a transversalidade das ações em educação especial dentro do ensino regular, assim como promover o desenvolvimento de recursos didáticos e pedagógicos que eliminem as barreiras no processo de aprendizagem e garantir a continuidade dos estudos nos demais níveis e modalidades.

O decreto ainda prevê, em seus artigos $4^{\circ}$ e $5^{\circ}$, que o poder público deve estimular o acesso ao atendimento educacional especializado de forma a complementar ou suplementar o ensino regular, bem como a União deve prestar apoio técnico e financeiro aos sistemas públicos de ensino e às instituições comunitárias e filantrópicas sem fins lucrativos, com o objetivo de ampliar a oferta de atendimento educacional especializado. No entanto, para receber este apoio técnico e financeiro, os requisitos para a participação, estabelecidos pelo Ministério da Educação, deverão ser atendidos. Para Sanches e Teodoro (2006), este movimento evoluiu e afirmou-se a partir de sucessivos trabalhos científicos e legislativos. A própria ruptura com a Educação Especial se dá com a Conferência Mundial sobre Educação para Todos, em Jomtien, Tailândia (1990), reforçando-se com a Conferência Mundial sobre as Necessidades Educativas Especiais que deu origem a Declaração de Salamanca (1994), 
supramencionada. Todos esses documentos auxiliaram no processo de aquisição de direitos pelas pessoas com necessidades especiais e da plena igualdade de oportunidades a todos, inclusive destacando a importância da inclusão nos cursos regulares de escolarização.

\title{
Resolução CNE/CEB nº 4/2009
}

Por meio da Resolução CNE/CEB n. ${ }^{\circ}$ 4/2009 são instituídas as Diretrizes Operacionais para o Atendimento Educacional Especializado na Educação Básica, modalidade Educação Especial, sendo estabelecidas as formas de atendimento em "salas de recursos multifuncionais ou em centros de Atendimento Educacional Especializado da rede pública ou de instituições comunitárias, confessionais ou filantrópicas sem fins lucrativos", conforme disposto em seu art. $1^{\circ}$, verbis:

\begin{abstract}
Art. $1^{\circ}$ Para a implementação do Decreto $n^{\circ} 6.571 / 2008$, os sistemas de ensino devem matricular os alunos com deficiência, transtornos globais do desenvolvimento e altas habilidades/superdotação nas classes comuns do ensino regular e no Atendimento Educacional Especializado (AEE), ofertado em salas de recursos multifuncionais ou em centros de Atendimento Educacional Especializado da rede pública ou de instituições comunitárias, confessionais ou filantrópicas sem fins lucrativos.
\end{abstract}

A oferta desse atendimento deve ser institucionalizada, prevendo-se a sala de recursos multifuncionais, elaboração do plano de Atendimento Escolar Especializado (AEE), professores para o exercício da docência no AEE, profissionais como tradutor e intérprete da Língua Brasileira de Sinais, guia-intérprete e demais profissionais necessários para atividades de apoio. O Parecer $n^{\circ} 13$ do CNE/CEB, homologado em 2009, regulamentou o Decreto $n^{\circ} 6.571$ e a Resolução CNE/CEB $n^{\circ}$ 4/2009, definindo o AEE em turno contrário ao da escolarização, visando "garantir o acesso dos alunos à educação comum e disponibilizando os serviços e apoios nas classes comuns da rede regular de ensino". Dias (2011, p. 59) instrui que, em termos de legislação, ocorreu uma grande conquista para os alunos com deficiência uma vez que o Estado assumiu os custos do AEE complementar ou suplementar e "reconheceu o direito à diferença como direito à equiparação de oportunidades".

A Resolução em questão surge como um dos dispositivos que conferem operacionalidade à Política Nacional de Educação Especial na perspectiva da Educação Inclusiva (2008), pois define as diretrizes do atendimento educacional especializado, delimitando quais instituições podem oferecê-lo e como esse oferecimento deve ser um suporte à presença do aluno nas escolas regulares. Esta ênfase no contexto escolar comum altera o plano normativo da política educacional brasileira para a Educação Especial, pois abandona-se o discurso da excepcionalidade da escolarização em espaços exclusivamente especializados - classes especiais e escolas especiais (KASSAR; REBELO, 2011).

Esta resolução define o alunado que é público-alvo para o $\mathrm{AEE}$, além de apresentar detalhamento relativo aos diferentes aspectos que integram as prioridades. $\mathrm{O}$ art. $8^{\circ}$ indica que "serão contabilizados duplamente, no âmbito do FUNDEB, de acordo com o Decreto $n^{\circ} 6.571 / 2008$, os alunos matriculados em classe comum do ensino regular público que tiverem matrícula concomitante no AEE". Em seguida, no mesmo artigo, encontra-se a afirmação: "O financiamento da matrícula no AEE é 
condicionado à matrícula no ensino regular da rede pública, conforme registro no Censo escolar/MEC/INEP do ano anterior...". Para além desse pressuposto vinculador, o texto da resolução indica que é de competência dos professores que "atuam na sala de recursos multifuncionais ou centros de AEE" a elaboração e execução do "plano do AEE", em articulação com os demais professores do ensino regular. Percebe-se, portanto, a necessidade de planejamento e de articulação entre educação especializada e ensino comum.

No que se refere à formação do professor responsável pelo $A E E$, as indicações da referida resolução são bastante genéricas: "o professor deve ter formação inicial que o habilite para o exercício da docência e a formação específica para a Educação Especial" (Art. 12). Pode-se supor que essa formação específica será bastante diversificada, considerando as potencialidades de formação e os quadros existentes nos diferentes estados brasileiros. Quanto às diretrizes para a ação desses profissionais, o Art. 13 indica que são atribuições do professor do Atendimento Educacional Especializado:

\footnotetext{
I - identificar, elaborar, produzir e organizar serviços, recursos pedagógicos, de acessibilidade e estratégias considerando as necessidades específicas dos alunos público-alvo da Educação Especial;

II - elaborar e executar plano de Atendimento Educacional Especializado, avaliando a funcionalidade e a aplicabilidade dos recursos pedagógicos e de acessibilidade;

III - organizar o tipo e o número de atendimentos aos alunos na sala de recursos multifuncionais;

IV - acompanhar a funcionalidade e a aplicabilidade dos recursos pedagógicos e de acessibilidade na sala de aula comum do ensino regular, bem como em outros ambientes da escola;

V - estabelecer parcerias com as áreas intersetoriais na elaboração de estratégias e na disponibilização de recursos de acessibilidade;

VI - orientar professores e famílias sobre os recursos pedagógicos e de acessibilidade utilizados pelo aluno;

VII - ensinar e usar a tecnologia assistida de forma a ampliar habilidades funcionais dos alunos, promovendo autonomia e participação;

VIII - estabelecer articulação com os professores da sala de aula comum, visando à disponibilização dos serviços, dos recursos pedagógicos e de acessibilidade e das estratégias que promovem a participação dos alunos nas atividades escolares. (grifos nosso).
}

Embora tenhamos que admitir a grande amplitude das ações e a possibilidade interpretativa de práticas centradas no atendimento direto ao aluno, é necessário que se identifique a potencial valorização do trabalho compartilhado com outros profissionais, principalmente o docente do ensino comum, como indicam os incisos IV, VI e VIII.

São ainda tímidas as indicações apresentadas pela Resolução 04/2009 do CNE quanto a essa mudança de perspectiva que valoriza uma ação mais sistêmica do educador especializado. No entanto, para que se trabalhe no sentido de tornar viável essa mudança, será necessário que avancemos no debate contemporâneo que associa as diretrizes da Educação Especial àquelas da educação, que reconheçamos a necessidade de utilizar os recursos disponíveis, propondo que haja um refinamento 
de nossas práticas aliadas à capacidade de gestão. É necessário que se diga, no entanto, que este contexto de mudanças potenciais mostra a importância do professor especializado em Educação Especial para que se garanta a existência de percursos escolares satisfatórios e desafiadores para os alunos com deficiência. Essa importância respalda-se na centralidade da sala de recursos como o dispositivo pedagógico prioritário na política de Educação Especial contemporânea, considerada sua característica de não substituição do espaço da sala de aula comum para a escolarização. Além disso, as atribuições que implicam conexões/articulações entre o docente especializado e o professor do ensino comum abrem espaço para a discussão curricular necessária nos processos inclusivos.

O que se observa, então, é que a Resolução CNE/CEB $n^{\circ}$ 4/2009 reafirma o caráter da Educação Especial como ação complementar ou suplementar e não mais substitutiva à escolarização no ensino comum, como ocorria em classes e escolas especiais.

\section{A Lei $n^{\circ}$ 13.146/2015: Institui a Lei Brasileira de Inclusão da Pessoa com Deficiência (Estatuto da Pessoa com Deficiência)}

O Brasil é signatário da Convenção de Nova York (2007), tratado de direitos humanos e que gera efeitos como emenda constitucional. O Estatuto da Pessoa com Deficiência (EPD) veio regulamentar a referida Convenção, como se percebe da leitura do art. $1^{\circ}$ :

É instituída a Lei Brasileira de Inclusão da Pessoa com Deficiência (Estatuto da Pessoa com Deficiência), destinada a assegurar e a promover, em condições de igualdade, o exercício dos direitos e das liberdades fundamentais por pessoa com deficiência, visando à sua inclusão social e cidadania. (grifo nosso).

A análise do caso concreto passou a ser pilar nessa recente codificação e como são alterações significativas justificam a importância do tema tanto para as pessoas com deficiência e sociedade quanto para os profissionais do direito. Deste modo tem-se que a interdição de pessoas com deficiência, agora não mais consideradas incapazes, não existe. E a regra passa a ser exceção, pois a curatela se dá apenas em situações excepcionais, como as de cunho patrimonial. É a dicção do art. 85 do Estatuto da Pessoa com Deficiência (EPD), ipsis litteris:

Art. 85. A curatela afetará tão somente os atos relacionados aos direitos de natureza patrimonial e negocial.

§ 10 A definição da curatela não alcança o direito ao próprio corpo, à sexualidade, ao matrimônio, à privacidade, à educação, à saúde, ao trabalho e ao voto.

§ 20 A curatela constitui medida extraordinária, devendo constar da sentença as razões e motivações de sua definição, preservados os interesses do curatelado.

§ 3o No caso de pessoa em situação de institucionalização, ao nomear curador, o juiz deve dar preferência a pessoa que tenha vínculo de natureza familiar, afetiva ou comunitária com o curatelado. (grifo nosso). 
As pessoas com deficiência passaram, a partir da entrada em vigor do EPD, a ser consideradas capazes para os atos da vida civil, trazendo modificações nos institutos da interdição e curatela. O EPD e suas revogações de grande parte dos artigos $3^{\circ}$ e $4^{\circ}$ do código civil retiram a pessoa portadora de transtorno mental do rol dos incapazes. In verbis:

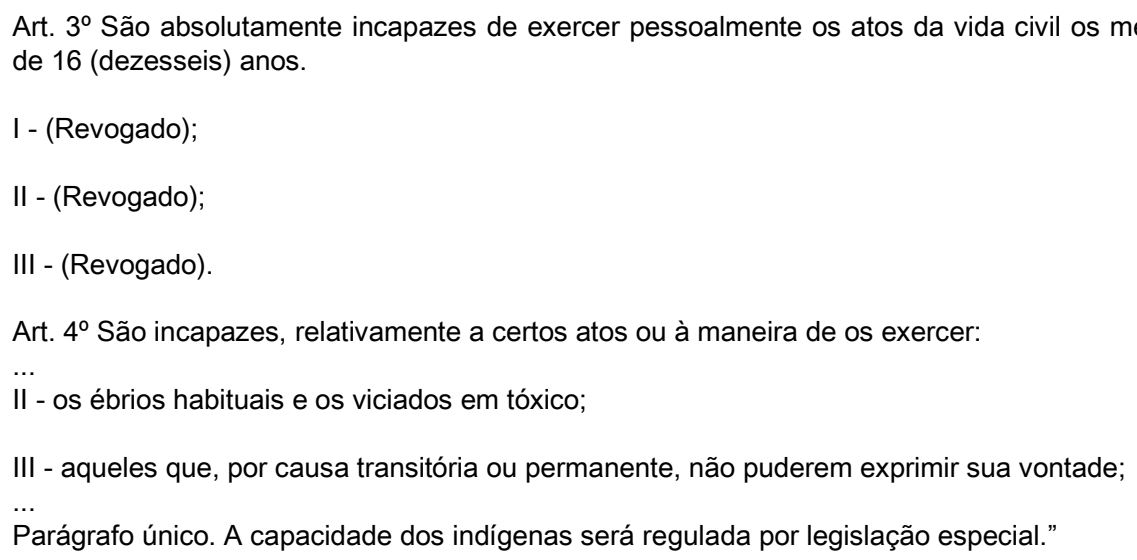

Deste modo, a pessoa que possuir qualquer deficiência não será somente por este fato de ser portadora que será inserida no rol dos incapazes. A referida modificação representa um notável avanço na legislação brasileira para a proteção da dignidade da pessoa com deficiência. Isto porque a regra passa a ser a garantia do exercício da capacidade legal por parte do portador de transtorno mental, em igualdade de condições com os demais sujeitos (artigo 84, EPD).

A curatela passa a ter índole de medida excepcional, a ser adotada somente quando e na medida em que for necessária. Foram, então, revogados os incisos I, II e IV, do artigo 1.767, do Código Civil (Lei no 10.406, de 10 de janeiro de 2002), em que se afirmava que os portadores de transtorno mental estariam sujeitos à curatela. Diz textualmente a nova lei em seu artigo 84 , parágrafo $3^{\circ}$, que a curatela deverá ser "proporcional às necessidades e às circunstâncias de cada caso, e durará o menor tempo possível". Portanto, preza-se a análise de cada caso concreto. No brilhante comentário do professor Tartuce (2015):

[...] parece-nos que o sistema de incapacidades deixou de ter um modelo rígido, passando a ser mais maleável, pensado a partir das circunstâncias do caso concreto e em prol da inclusão das pessoas com deficiência, tutelando a sua dignidade e a sua interação social. Isso já tinha ocorrido na comparação das redações do Código Civil de 2002 e do seu antecessor. Como é notório, a codificação material de 1916 mencionava os surdos-mudos que não pudessem se expressar como absolutamente incapazes (art. $5^{\circ}$, III, do CC/1916). A norma então em vigor, antes das recentes alterações ora comentadas, tratava das pessoas que, por causa transitória ou definitiva, não pudessem exprimir sua vontade, agora tidas como relativamente incapazes, reafirme-se.

A regra passou a ser exceção, como frisamos. Em situações excepcionais, a pessoa com deficiência mental ou intelectual poderá ser submetida a curatela, no seu interesse exclusivo e não de 
parentes ou terceiros. Essa curatela, ao contrário da interdição total anterior, deve ser, de acordo com o artigo 84 do EPD, proporcional às necessidades e circunstâncias de cada caso "e durará o menor tempo possível". Tem sua essência de medida protetiva e não de interdição de exercício de direitos.

Sobre o tema, Tartuce (2015) elucida:

Em suma, não existe mais, no sistema privado brasileiro, pessoa absolutamente incapaz que seja maior de idade. Como consequência, não há que se falar mais em ação de interdição absoluta no nosso sistema civil, pois os menores não são interditados. Todas as pessoas com deficiência, das quais tratava o comando anterior, passam a ser, em regra, plenamente capazes para o Direito Civil, o que visa a sua plena inclusão social, em prol de sua dignidade.

Desse modo, não existirá mais o instituto da interdição tendo como sujeito a pessoa com deficiência, pois não mais poderá lhe vedar o exercício dos atos da vida civil. E o instituto da curatela em grau de excepcionalidade, somente para aqueles atos de cunho patrimonial.

Entende-se, então, que por ser lei especial o EPC prevalece sobre o Código de Processo Civil (lex specialis derrogat lex), não falando em interdição de pessoas capazes. Visto que esse instituto fica em desuso para as pessoas com deficiência mesmo que em seu texto trate de "interdição". O que se tem em caráter excepcional é a curatela a fim de ajudar o próprio curatelado e de caráter provisório, somente para atos de cunho patrimonial.

Sendo assim, embora haja divergência doutrinária acerca da efetividade dessa lei, é certo que trouxe várias modificações na legislação civil e processual civil, principalmente no que pertine ao processo de curatela, não mais se aplicando a interdição, tendo em vista que as pessoas com sofrimento psíquico não mais estão incluídas no rol de pessoas incapazes, já que o EPD revogou os dispositivos alusentes à incapacidade dos deficientes mentais no Código Civil.

\section{CONSIDERAÇÕES FINAIS}

Após averiguar a legislação para pessoas com deficiência e o processo da educação inclusiva no cenário atual, pôde-se evidenciar que ainda há uma longa distância a percorrer quando o assunto é a efetivação dessas normas.

A legislação tem dado suporte para que a Educação Especial no Brasil do século XXI consista em adequar os seus sistemas sociais para avançar na inclusão. Pós Declaração dos Direitos Humanos de 1948, pós Constituição de 1988, pós Declaração de Salamanca de 1994, aumentou-se muito a discussão sobre a Educação Especial no Brasil, o que já constitui uma mudança de paradigma. Diante de diversas leis e diretrizes institucionais, vê-se que a inclusão do aluno com deficiência tem o inquestionável mérito da socialização e que é crescente o processo de transformação das concepções teóricas e das práticas da Educação Especial.

Tal como os aspectos discutidos acima, outros mais têm sido levantados, exemplificando o receio que nações, governos e demais implicados possam ter quanto a este processo de 
transformação da educação de um paradigma de exclusão para um que seja de inclusão. Por exemplo, existem preocupações expressas a respeito do nível de capacitação dos profissionais da educação regular e da educação especial, e a respeito da falta de investimento no assunto, e assim por diante. Tais preocupações, ainda que altamente relevantes, muitas vezes acabam impedindo a implementação de programas educacionais inclusivos, ou, no mínimo, acabam sendo usadas como justificativas para a manutenção de sistemas paralelos de ensino, o que por sua vez reforça uma certa contradição entre o que se verifica no discurso e na prática.

Foi possível perceber que são necessárias muitas ações capazes de possibilitar a implantação destas leis na prática cotidiana das escolas, através de condições adequadas para a equipe técnica que se dedica ao projeto. Além disso, é necessário suporte técnico aos participantes, pessoal da escola e público em geral, bem como assistir às escolas para obtenção de recursos necessários e o desenvolvimento de inovações pedagógicas direcionadas às necessidades do aluno. Além disso, devem ser oferecidas oportunidades de desenvolvimento aos membros participantes do projeto, fornecendo aos professores informações relacionadas com as dificuldades da criança, com o seu processo de aprendizagem, de desenvolvimento social e individual, fazendo com que os professores busquem desenvolver ao máximo as potencialidades da criança, propiciando formas mais adequadas para o trabalho e criando novas alternativas para o seu desenvolvimento.

Destarte, as políticas educacionais na perspectiva inclusiva são resultados de programas que não têm contribuído para uma educação pública de qualidade, quando não há sequer disponibilidade de novos recursos financeiros à Educação Especial, tão necessários para a materialização das ações. Essa questão leva a refletir que em tempos de inclusão escolar, a reconstrução do sistema educacional, no sentido de romper as barreiras de acesso deve garantir permanência e construa conhecimento, indo muito além de implementações de leis; mas isto requer mudanças na estrutura do ensino, uma vez que os direitos precisam ultrapassar o plano do meramente instituído legalmente.

No cenário da educação inclusiva, verifica-se o distanciamento entre a realidade empírica da escola, que se pretende inclusiva, e o que se espera dela por determinação legal. Caracteriza-se uma situação em que se demandam leis e políticas que garantam acesso à educação, apoios, ajustes e adaptações necessárias, visando à aprendizagem e à sustentabilidade dos sistemas de ensino para o cumprimento de suas finalidades. Nesse particular, o ordenamento jurídico constitui base sólida para fomentar o cumprimento dos direitos dos estudantes e a eficácia da escola, com eliminação de ambiguidades e contradições que possam postergar ou dificultar esses propósitos.

Caso o Brasil assegurasse realmente tudo que se apresenta escrito na lei, teríamos um país devidamente inclusivo, uma nação que se preocuparia com a situação social dos indivíduos, sendo necessário ainda, que tenhamos a convicção que não se transforma atitudes da noite para o dia, sejam elas individuais ou coletivas, levando em conta toda a nossa história de exclusão e preconceito. Porém, isso também não inviabiliza uma mudança atitudinal e a Declaração de Salamanca é um documento norteador para que essas modificações - também trazidas em outras legislações - sejam alcançadas e trabalhadas no processo de inclusão e que uma educação para todos aconteça de fato. 


\section{REFERÊNCIAS}

1. BRASIL. Ministério da Educação. Secretaria de Educação Especial. Resolução $n^{\circ}$ 4, de 2 de outubro de 2009. Diretrizes Operacionais para o Atendimento Educacional Especializado na Educação Básica, modalidade Educação Especial. Disponível em: http://peei.mec.gov.br/ arquivos/Resol_4_2009_CNE_CEB.pdf Acesso em: Acesso em: 28 Jun 2016 Presidência da República. Decreto № 7.611, de 17 de novembro de 2011. Dispõe sobre a educação especial, o atendimento educacional especializado e dá outras providências. Disponível em: Acesso em: 28 Jun 2016

Decreto $n^{\circ} 6.571$, de 17 de setembro de 2008. Dispõe sobre o atendimento educacional especializado, regulamenta o parágrafo único do art. 60 da Lei $n^{\circ}$ 9.394, de 20 de dezembro de 1996, e acrescenta dispositivo ao Decreto $n^{\circ}$ 6.253, de 13 de novembro de 2007. Casa Civil; Subchefia para Assuntos Jurídicos, Brasília, DF, set. 2008. Disponível em: http://www.planalto.gov.br/ccivil_03/_ato2007-2010/2008/Decreto/D6571.htm. Acesso em: 28 Jun 2016.

Decreto $n^{\circ} 7.611$, de 17 de novembro de 2011. Dispõe sobre a educação especial, o atendimento educacional especializado e dá outras providências. Casa Civil; Subchefia para Assuntos Jurídicos, Brasília, DF, nov., 2011. Disponível em: http://www.planalto.gov.br/ccivil_03/_Ato2011-2014/2011/Decreto/D7611.htm. Acesso em: 28 Jun 2016.

Parecer CEB/CNE $n^{\circ} 13$, de 24 de setembro de 2009. Diretrizes Operacionais para o atendimento educacional especializado na Educação Básica, modalidade Educação Especial. Diário Oficial da União, Brasília, 2009. Disponível em: http://portal.mec.gov.br/dmdocuments/pceb013_09_homolog.pdf. Acesso em: 28 Jun 2016. Ministério da Educação. Secretaria de Educação Especial. Política Nacional de Educação Especial na perspectiva da educação inclusiva. Brasília, DF, 2008. <http://portal.mec.gov.br/seesp/arquivos/pdf/salamanca.pdf> Acesso em 28jun2016

8. BUENO, J. G. S. Educação especial brasileira: integração/segregação do aluno diferente. São Paulo: Educ, 1993.

9. DIAS, M. C. Educação um direito prioritário. Revista Veras, v.1, n.1, 2011. 
10. DUTRA, Claudia Pereira. Editorial. In: Inclusão - Revista da Educação Especial. Ano 2, n. 3, dez./2006. Disponível em: <http://portal.mec.gov.br/seesp/arquivos/pdf/revistainclusao2.pdf. Acesso em: 26 Jun. 2016.

11. FOUCAULT, Michel. Os Anormais. São Paulo: Martins Fontes, 2001. $1^{\text {a }}$ ed.

12. KASSAR, M. C. M.; REBELO, A. S. O "especial" na educação, o atendimento especializado e a educação especial. In: SEMINÁRIO NACIONAL DE PESQUISA EM EDUCAÇÃO ESPECIAL. Prática Pedagógica na Educação Especial: multiplicidade do atendimento educacional especializado, 4., 2011, Nova Almeida. Anais. Nova Almeida, 2011. CD-ROM.

13. MENDES, E. G. Perspectivas para a construção da escola inclusiva no Brasil. In: PALHARES. 2001.

14. RAGONESI, M. E. M. M. Psicologia escolar: pensamento crítico e práticas profissionais. 1997. 48p. Tese (Doutorado em educação) - Universidade de São Paulo, São Paulo, 1997.

15. SANCHES, I.; TEODORO, A. Da integração à inclusão escolar: cruzando perspectivas e conceitos. Revista Lusófona de Educação, n 8, 2006.

16. SANTOS, Mônica Pereira dos. Educação Inclusiva e a Declaração de Salamanca: consequências ao Sistema Educacional Brasileiro. ano 10, no.22 - 2000, pp. 34-40. Disponível em: <http://www.lapeade.com.br/publicacoes/artigos/Educacao\%20Inclusiva\%20e\%20a\%20Declaracao \%20de\%20Salamanca.pdf> Acesso em: 28 Jun 2016.

17. TARTUCE, Flávio. Alterações do Código Civil pela lei 13.146/2015 (Estatuto da Pessoa com Deficiência). Repercussões para o Direito de Família e Confrontações com o Novo CPC. Parte I [Internet]. Julho $2015 . \quad$ Disponível em:. http://www.migalhas.com.br/FamiliaeSucessoes/104,MI224217,21048-

Alteracoes+do+Codigo+Civil+pela+lei+131462015+Estatuto+da+Pessoa+com> Acesso em 20jun2016.

\section{Gabriela Alves de Arruda:}

Professora do Departamento de Direito da Faculdade de Integração do Sertão (FIS - Serra Talhada/PE). 


\section{Dennys Dikson:}

Professor Adjunto do Departamento de Letras da Universidade Federal Rural de Pernambuco, Unidade Acadêmica de Garanhuns.

\section{Como citar este documento:}

ARRUDA, Gabriela Alves de; DIKSON, Dennys. EDUCAÇÃO INCLUSIVA, LEGISLAÇÃO E IMPLEMENTAÇÃO. Reflexão e Ação, Santa Cruz do Sul, v. 26, n. 2, ago. 2018. ISSN 1982-9949. Disponível em: <https://online.unisc.br/seer/index.php/reflex/article/view/8177>. Acesso em: doi: http://dx.doi.org/10.17058/rea.v26i2.8177. 